\title{
ÍNDICE DE ÁREA FOLIAR, INTERCEPTAÇÃO LUMINOSA E ACÚMULO DE FORRAGEM EM PASTAGENS DE Cynodon spp. SOB DIFERENTES INTENSIDADES DE PASTEJO
} \author{
Luis Felipe de Moura Pinto ${ }^{1,3}$ \\ ${ }^{1}$ Pós-Graduando do Depto. de Produção Animal - ESALQ/USP. \\ ${ }^{2}$ Depto. de Produção Animal - ESALQ/USP, C.P. 9 - CEP:13418-900 - Piracicaba, SP. \\ ${ }^{3}$ Bolsista do CAPES. \\ ${ }^{4}$ Bolsista da FAPESP. \\ *e-mail: scdsilva@carpa.ciagri.usp.br
}

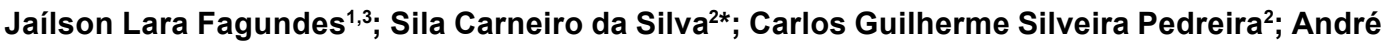
Fischer Sbrissia ${ }^{1,4}$; Roberta Aparecida Carnevallii, ${ }^{1,3}$ Carlos Augusto Brandão de Carvalho ${ }^{1,4}$;

RESUMO: Avaliou-se o índice de área foliar (IAF), interceptação luminosa (IL) e acúmulo de matéria seca em três cultivares de Cynodon spp. (Tifton-85, Florakirk e Coastcross) submetidos a quatro intensidades de pastejo $(5,10,15$ e $20 \mathrm{~cm})$ estabelecidas com ovinos em regime de lotação contínua. $O$ delineamento experimental utilizado foi 0 de blocos completos casualizados com quatro repetições e parcelas sub-divididas, onde na parcela foram alocados os cultivares e na sub-parcela as intensidades de pastejo. Os maiores valores de IAF foram encontrados para Tifton-85. As taxas de acúmulo de matéria seca foram semelhantes em todos os tratamentos. Tifton-85 apresentou como amplitude ótima de uso condições de pasto que variaram de 5 a $15 \mathrm{~cm}$. Para Florakirk essa amplitude foi até $20 \mathrm{~cm}$ e para Coastcross o limite foi superior a $20 \mathrm{~cm}$. Diferentes cultivares apresentaram requerimentos variados de manejo de desfolha quando o objetivo foi o uso eficiente da luz e dos demais fatores de crescimento para elevados índices de utilização da forragem produzida.

Palavras-chave: Tifton-85, Florakirk, Coastcross, manejo do pastejo, lotação contínua

\section{CANOPY CHARACTERISTICS AND HERBAGE ACCUMULATION OF Cynodon spp. SUBMITTED TO DIFFERENT GRAZING INTENSITIES}

ABSTRACT: Leaf area index (LAI), light interception and herbage accumulation were evaluated for three Cynodon spp. cultivars (Tifton-85, Florakirk and Coastcross) submitted to four grazing intensities $(5,10,15$ and $20 \mathrm{~cm})$ established by sheep under a continuous stocking management. A complete randomised block design was used with four replications, with treatements in a split-plot arrangement. Grass cultivars were allocated to plots and grazing intensities to subplots. The largest values of LAl were observed for Tifton-85. Rates of dry matter accumulation were similar for all treatments. Tifton-85 presented a narrower optimal range for pasture conditions $(5$ to $15 \mathrm{~cm})$ as compared to Florakirk $(5-20 \mathrm{~cm})$ and Coastcross $(5-20+\mathrm{cm})$. Different grass cultivars presented different grazing management requirements in situations where the efficient use of light and high levels of herbage utilisation were targeted.

Key words: Tifton-85, Florakirk, Coastcross, grazing management, continuous stocking

\section{INTRODUÇÃO}

A baixa produtividade das pastagens é uma das principais causas da baixa competitividade e lucratividade da nossa pecuária em relação a outras explorações econômicas da terra. A reversão deste quadro passa por um processo de revisão dos conceitos sobre pastagens e a necessidade de intensificação planejada de seu uso. Dentro deste contexto, a exploração de espécies melhoradas, capazes de produzir em quantidade e com qualidade, deve ser encarada como fundamental, e é neste cenário que os capins do gênero Cynodon têm-se destacado, pois possuem elevado potencial de produção, bom valor nutritivo e grande flexibilidade de uso.

Hodgson (1990) considera que as variáveis do pasto que apresentam uma maior consistência sobre a produção de forragem são a altura e o índice de área foliar (IAF), especialmente 
em se tratando de gramíneas forrageiras prostradas, de porte baixo e com alto potencial de perfilhamento. Num valor de IAF chamado "ótimo" $\left(\mathrm{IAF}_{\text {ótimo }}\right)$ a interceptação de aproximadamente toda a luz incidente com um mínimo de autosombreamento proporcionaria o máximo valor de taxa de crescimento da cultura (TCC, peso de matéria seca acumulado por unidade de área por unidade de tempo) (Watson, 1958; Brown \& Blaser, 1968; Rhodes, 1973). Com o aumento no índice de área foliar ocorre um aumento na interceptação luminosa e na eficiência de uso da radiação fotossinteticamente ativa, o que ocasiona uma aceleração na taxa de crescimento em condições ambientais favoráveis (Brown \& Blaser, 1968; Humphreys, 1966).

Apesar de algumas limitações quanto ao uso do conceito de IAF no manejo de pastagens, que surgem principalmente por mudanças nas características fotossintéticas, na arquitetura e composição botânica do pasto, Brown \& Blaser (1968) concluíram que o IAF, relacionado à interceptação de luz, parece uma forma útil para entender a produção de forragem e o desenvolvimento de melhores variedades e práticas de manejo.

Assim, o presente estudo teve por objetivo avaliar o efeito da intensidade de pastejo sobre a interceptação luminosa, índice de área foliar e acúmulo de forragem em pastagens de Cynodon spp. pastejadas por ovinos em regime de lotação contínua.

\section{MATERIAL E MÉTODOS}

O experimento foi conduzido na Unidade Experimental de Plantas Forrageiras (UEPF) em área do Departamento de Produção Animal da ESALQ/ USP, Piracicaba-SP. O experimento foi instalado em solo classificado como terra roxa estruturada eutrófica, cuja análise de terra revelou os seguinte resultados: ph $\left(\mathrm{CaCl}_{2}\right)=5,4 ; \mathrm{MO}\left(\mathrm{g} \mathrm{kg}^{-1}\right)=37,0$;
$\mathrm{P}\left(\mathrm{mg} \mathrm{dm}^{-3}\right)=99 ; \mathrm{K}\left(\mathrm{cmol}_{\mathrm{c}}\right)=0,46 ; \mathrm{Ca}\left(\mathrm{cmol}_{\mathrm{c}}\right)=$ 7,50; $\mathrm{Mg}\left(\mathrm{cmol}_{\mathrm{c}}\right)=2,60 ; \mathrm{H}+\mathrm{Al}\left(\mathrm{cmol}_{\mathrm{c}}\right)=3,00 ; \mathrm{SB}$ $\left(\mathrm{cmol}_{\mathrm{c}}\right)=10,60 ; \mathrm{T}\left(\mathrm{cmol}_{\mathrm{c}}\right)=13,60$ e V(\%)=78,0. Devido à elevada fertilidade do solo não foram realizadas práticas de correção da fertilidade no momento da implantação do experimento. Durante o período experimental (3 de julho a 31 de dezembro de 1998), a temperatura média diária máxima foi de $30,0^{\circ} \mathrm{C}$ e a mínima de $10,8^{\circ} \mathrm{C}$. Já a precipitação pluvial total foi de $626,5 \mathrm{~mm}$ e a umidade relativa do ar variou entre 76 e $83 \%$. Os demais dados meteorológicos encontram-se na TABELA 1.

O delineamento foi o de blocos completos casualizados, em parcelas subdivididas (split-plot), com quatro repetições. Os tratamentos corresponderam a três cultivares de Cynodon spp., Tifton-85, Florakirk e Coastcross, que foram alocados às parcelas e de quatro condições de pasto, geradas por ovinos sob regime de lotação contínua, alocadas nas sub-parcelas. Cada condição de pasto correspondeu a uma altura média de 5,10 , 15 e $20 \mathrm{~cm}$, mantida relativamente constante através da adição ou retirada de animais das parcelas durante o transcorrer do experimento. O ensaio apresentou um total de 48 unidades experimentais (4 blocos x 12 unidades/ bloco) com uma área média de $400 \mathrm{~m}^{2}$ cada, separadas por tela de 1,20 $\mathrm{m}$ de altura para delimitação dos piquetes (unidades experimentais) e contenção dos animais. A área experimental total compreendeu 2,0 ha.

Em 3 de junho de 1998 os animais foram colocados nas unidades experimentais que haviam atingido a altura pré-determinada para os tratamentos. À medida que as demais unidades experimentais atingiam a altura desejada, animais eram adicionados dando início ao processo de pastejo. Durante a condução do experimento, de 03 de julho a 31 de dezembro de 1998, foram realizadas quatro adubações nitrogenadas com sulfato de amônio, num total de $155 \mathrm{~kg} \mathrm{~N} \mathrm{ha}^{-1}$.

TABELA 1 - Precipitação pluvial, radiação solar global e temperaturas médias mensais do ar (máxima, mínima e média) durante o período experimental.

\begin{tabular}{lccccc}
\hline \multicolumn{1}{c}{ Mês } & $\begin{array}{c}\text { Radiação } \\
\text { Global }\left(\mathrm{cal} \mathrm{cm} \mathrm{cm}^{-2}\right)\end{array}$ & $\begin{array}{c}\text { Precipitação } \\
(\mathrm{mm})\end{array}$ & \multicolumn{3}{c}{ Temperatura $\left({ }^{\circ} \mathrm{C}\right)$} \\
\cline { 4 - 6 } & 299 & 13,9 & 25,9 & 10,8 & Máxima \\
\hline Julho & 310 & 21,8 & 27,4 & 14,4 & 20,9 \\
\hline Agosto & 335 & 89,3 & 27,7 & 15,3 & 21,5 \\
Setembro & 369 & 183,1 & 27,1 & 16,3 & 21,7 \\
Outubro & 474 & 26,6 & 30,0 & 16,5 & 23,2 \\
Novembro & 441 & 292,0 & 30,0 & 19,2 & 24,6 \\
\hline Dezembro & & & & & \\
\hline
\end{tabular}

Fonte: ESALQ (1999) 
A intensidade de pastejo (altura) foi monitorada através da tomada de 20 medidas de altura, em cada parcela, realizada com o prato ascendente ("rising plate meter") duas vezes por semana, sendo obtida a altura comprimida do pasto. Esta, por sua vez, foi convertida para altura não comprimida através de fator de conversão gerado entre o prato ascendente e a régua ("sward stick") para cada cultivar em cada mês. Este valor de altura foi então usado como referência para o monitoramento dos tratamentos.

Em cada unidade experimental o acúmulo de forragem foi medido dentro de 3 gaiolas de exclusão $(70 \mathrm{~cm} \times 70 \mathrm{~cm} \times 70 \mathrm{~cm})$ observando-se um intervalo de 21 dias entre amostragens sucessivas. No dia da colocação da gaiola eram tomadas 5 leitura com o prato ascendente e, 21 dias depois, outra cinco leituras quando da mudança de posição. Após a amostragem as gaiolas eram rotacionadas nas unidades experimentais e ancoradas em novos pontos representativos da condição (altura média) do pasto no momento do rodízio.

Os cálculos de acúmulo de forragem foram feitos com base no método agronômico da diferença (Davies et al., 1993). Uma vez ao mês era feita a calibração entre altura e massa de forragem, com a finalidade de relacionar a altura média do pasto com a massa de forragem existente e também para o cálculo de acúmulo de matéria seca, minimizando o número de amostragens destrutivas. Com anéis de $0,25 \mathrm{~m}^{2}$ de área, foram escolhidos dois pontos de cada parcela procurando sempre o ponto mais baixo e o ponto mais alto a fim de se obter a maior amplitude possível de alturas. Foi medida a altura do pasto dentro do anel com a régua e com o prato ascendente, e a forragem foi cortada ao nível o solo, lavada para eliminação de resíduos de terra e fezes, seca em estufa a $65{ }^{\circ} \mathrm{C}$ até massa constante e pesada. Assim, após determinada a massa seca, estabeleceu-se a regressão linear entre altura e massa de forragem para cada cultivar. A partir destas regressões os valores de altura do pasto eram transformados em massa de forragem e o acúmulo de matéria seca calculado.

Para avaliação do índice de área foliar (IAF) foram cortados 2 quadrados de $25 \mathrm{~cm}$ de lado por unidade experimental respeitando um intervalo mensal entre amostragens. A forragem foi cortada ao nível do solo e levada para laboratório no menor espaço de tempo possível. Ao final da colheita as amostras eram lavadas, sub-amostradas e fracionadas manualmente em material vivo e morto. O material vivo foi fracionado em folhas (lâminas foliares) e hastes (haste e pseudohaste). Após a separação destes componentes, uma sub-amostra das lâminas verdes tinha sua área medida num integrador de área foliar marca LI-COR modelo LI3100. Posteriormente, eram levadas para secagem em estufa a $65^{\circ} \mathrm{C}$ até peso constante, juntamente com os demais componentes separados. Após secagem, as amostras eram pesadas. Através das relações obtidas entre peso seco e área de folhas foram calculadas a área total de folhas na área de coleta da amostra (625 $\mathrm{cm}^{2} /$ quadrado) e o IAF correspondente $\left(\mathrm{cm}^{2}\right.$ de folhas $/ \mathrm{cm}^{2}$ de solo).

As avaliações de interceptação luminosa da radiação solar fotossinteticamente ativa foram realizadas usando-se um fotômetro LI-COR (line quantum sensor) modelo LI-250. Foram tomadas 6 leituras em pontos representativos de cada unidade experimental, correspondentes às alturas dos tratamentos $(5,10,15$ e $20 \mathrm{~cm})$. As leituras foram realizadas ao redor das 12:00 horas sob céu claro, medindo-se a intensidade luminosa acima do relvado $\left(I_{0}\right)$ e aquela no nível do solo (I). A interceptação luminosa foi calculada como:

$$
\text { Interceptação }=\left(I_{0}-I\right) / I_{0}
$$

Os dados foram analisados utilizando-se o procedimento GLM do pacote estatístico SAS. Dentro deste procedimento a análise foi realizada pelo sub-procedimento de medidas repetidas no tempo, uma vez que as medições foram feitas ao longo de vários meses (SAS Institute, 1988). Utilizou-se o "LSMEANS" para a comparação de médias entre tratamentos.

\section{RESULTADOS E DISCUSSÃO}

Os dados referentes ao índice de área foliar (IAF) são mostrados na TABELA 2 e Figuras 1 e 2 . Houve diferenças entre meses $(P=0,0001)$, cultivares $(P=0,0001)$ e interação mês $x$ cultivar $(P=0,0001)$ as quais podem ser observadas na TABELA 2 e Figura 1. Houve diferenças referentes a altura $(P=0,0001))$ as quais podem ser observadas na TABELA 2 e Figura 2 e cultivar $x$ altura $(P=0,0357)$ observadas na TABELA 2.

Madakadze et al. (1998), trabalhando com Panicum virgatum, observaram diferenças na distribuição vertical de IAF entre as populações em ambos os anos de avaliação de seu estudo, havendo interação significativa entre tempo $x$ populações de Panicum x altura. Resultados semelhantes foram encontrados neste experimento, uma vez que ocorreu interação entre tempo $x$ cultivar e cultivar $\mathrm{x}$ altura. 
TABELA 2 - Índice de área foliar de julho a dezembro de 1998 para os tratamentos (Cultivar x Altura) experimentais.

\begin{tabular}{|c|c|c|c|c|c|}
\hline Altura & Tifton-85 & Florakirk & Coastcross & média & EPM \\
\hline & & & Julho & & \\
\hline 5 & $1,21^{\mathrm{Ca}}$ & $0,78^{\mathrm{Ba}}$ & $0,86^{\mathrm{Aa}}$ & $0,95^{\mathrm{C}}$ & 0,16 \\
\hline 10 & $2,13^{\mathrm{Ba}}$ & $1,61^{\mathrm{Aab}}$ & $1,24^{\mathrm{Ab}}$ & $1,66^{\mathrm{B}}$ & 0,16 \\
\hline 15 & $2,74 \mathrm{Ba}$ & $1,71^{\mathrm{Ab}}$ & $1,40^{\mathrm{Ab}}$ & $1,95^{\mathrm{B}}$ & 0,16 \\
\hline 20 & $3,67^{\mathrm{Aa}}$ & $2,06^{\mathrm{Ab}}$ & $1,59^{\mathrm{Ab}}$ & $2,44^{\mathrm{A}}$ & 0,16 \\
\hline média & $2,44^{\mathrm{a}}$ & $1,54^{b}$ & $1,27^{b}$ & & \\
\hline \multirow[t]{2}{*}{ EPM } & 0,13 & 0,13 & 0,13 & & \\
\hline & & & Agosto & & \\
\hline 5 & $0,84^{\mathrm{Da}}$ & $0,70^{\mathrm{Ba}}$ & $0,50^{\mathrm{Ba}}$ & $0,68^{c}$ & 0,16 \\
\hline 10 & $1,67^{\mathrm{Ca}}$ & $1,47^{\mathrm{ABa}}$ & $1,22{ }^{\mathrm{ABa}}$ & $1,45^{\mathrm{B}}$ & 0,16 \\
\hline 15 & $2,66^{\mathrm{Ba}}$ & $1,33^{\mathrm{ABb}}$ & $1,00^{\mathrm{ABb}}$ & $1,67^{\mathrm{B}}$ & 0,16 \\
\hline 20 & $3,71^{\mathrm{Aa}}$ & $2,04^{A b}$ & $1,37^{\mathrm{Ab}}$ & $2,37^{\mathrm{A}}$ & 0,16 \\
\hline média & $2,22^{a}$ & $1,38^{b}$ & $1,02^{b}$ & & \\
\hline \multirow[t]{2}{*}{ EPM } & 0,14 & 0,14 & 0,14 & & \\
\hline & & & Setembro & & \\
\hline 5 & $0,74^{\mathrm{Ca}}$ & $0,60^{\mathrm{Aa}}$ & $0,21^{\mathrm{Aa}}$ & $0,51^{\mathrm{C}}$ & 0,13 \\
\hline 10 & $1,02^{\mathrm{BCa}}$ & $0,75^{\mathrm{Aa}}$ & $0,53^{\mathrm{Aa}}$ & $0,77^{\mathrm{BC}}$ & 0,13 \\
\hline 15 & $1,57^{\mathrm{Ba}}$ & $0,91^{\mathrm{Ab}}$ & $0,66^{A b}$ & $1,05^{\mathrm{B}}$ & 0,13 \\
\hline 20 & $2,67^{\mathrm{Aa}}$ & $1,08^{\mathrm{Ab}}$ & $0,78^{A b}$ & $1,51^{\mathrm{A}}$ & 0,13 \\
\hline média & $1,50^{\mathrm{a}}$ & $0,83^{b}$ & $0,55^{b}$ & & \\
\hline \multirow[t]{2}{*}{ EPM } & 0,11 & 0,11 & 0,11 & & \\
\hline & & & Outubro & & \\
\hline 5 & $0,97^{\mathrm{Ca}}$ & $0,96^{\mathrm{Ba}}$ & $0,70^{\mathrm{Ba}}$ & $0,88^{\mathrm{C}}$ & 0,11 \\
\hline 10 & $1,92^{\mathrm{Ba}}$ & $1,58^{\mathrm{Aab}}$ & $1,30^{\mathrm{Ab}}$ & $1,60^{\mathrm{B}}$ & 0,11 \\
\hline 15 & $2,04 \mathrm{Ba}$ & $1,81^{\mathrm{Aa}}$ & $1,53 \mathrm{Aa}$ & $1,79^{\text {в }}$ & 0,11 \\
\hline 20 & $3,23^{\mathrm{Aa}}$ & $1,84^{\mathrm{Ab}}$ & $1,64^{\mathrm{Ab}}$ & $2,24^{\mathrm{A}}$ & 0,11 \\
\hline média & $2,04^{a}$ & $1,55^{b}$ & $1,29^{b}$ & & \\
\hline \multirow[t]{2}{*}{ EPM } & 0,10 & 0,10 & 0,10 & & \\
\hline & & & Novembro & & \\
\hline 5 & $0,89^{\mathrm{Ca}}$ & $0,77^{\mathrm{Aa}}$ & $0,68^{\mathrm{Aa}}$ & $0,78^{c}$ & 0,08 \\
\hline 10 & $1,09 \mathrm{Ca}$ & $0,92^{\mathrm{Aa}}$ & $1,06^{\mathrm{Aa}}$ & $1,03^{\mathrm{B}}$ & 0,08 \\
\hline 15 & $1,51^{\mathrm{Ba}}$ & $1,01^{\mathrm{Ab}}$ & $0,93^{\mathrm{Ab}}$ & $1,15^{\mathrm{AB}}$ & 0,08 \\
\hline 20 & $2,04^{\mathrm{Aa}}$ & $1,03^{A b}$ & $1,05^{A b}$ & $1,37^{A}$ & 0,08 \\
\hline média & $1,38^{a}$ & $0,93^{b}$ & $0,93^{b}$ & & \\
\hline \multirow[t]{2}{*}{ EPM } & 0,07 & 0,07 & 0,07 & & \\
\hline & & & Dezembro & & \\
\hline 5 & $0,59^{\mathrm{Ba}}$ & $0,49^{\mathrm{Ba}}$ & $0,66^{\mathrm{Aa}}$ & $0,58^{\mathrm{B}}$ & 0,11 \\
\hline 10 & $1,16^{\mathrm{Aa}}$ & $0,69^{\mathrm{Ba}}$ & $0,85^{\mathrm{Aa}}$ & $0,90^{A}$ & 0,11 \\
\hline 15 & $0,97^{\mathrm{ABa}}$ & $1,40^{\mathrm{Aa}}$ & $1,11^{\mathrm{Aa}}$ & $1,16^{A}$ & 0,11 \\
\hline 20 & $1,48^{\mathrm{Aa}}$ & $0,73^{\mathrm{Bb}}$ & $1,02^{\mathrm{Aab}}$ & $1,08^{A}$ & 0,11 \\
\hline média & $1,05^{\mathrm{a}}$ & $0,83^{\mathrm{a}}$ & $0,91^{\text {a }}$ & & \\
\hline EPM & 0,09 & 0,09 & 0,09 & & \\
\hline
\end{tabular}

Médias seguidas de mesma letra não diferem entre si $(P>0,05)$, letra maiúscula na coluna e minúscula na linha. EPM - erro padrão da média.

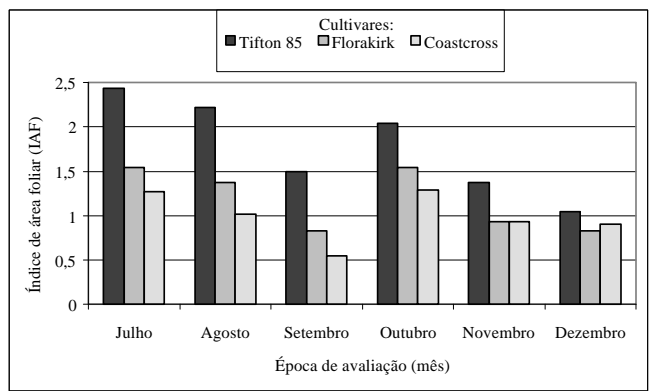

Figura 1 - Índice de área foliar em pastos de Cynodon spp. sob regime de lotação contínua e em diferentes épocas de avaliação.
Os valores de IAF encontrados no presente experimento variaram entre 0,21 e 3,71 (TABELA 2). Estes valores são bastante inferiores àqueles relatados por Brougham (1956; 1957) para plantas de clima temperado, particularmente azevém perene. Esse autor relatou que $95 \%$ de interceptação de luz foi obtida com um IAF igual a 5,0 e 3,5, respectivamente, para azevém e trevo branco. No entanto, Humphreys (1991) comentou que os valores do IAF crítico para pastagens, situam-se, normalmente entre 3 e 5 , sendo que nesta faixa a interceptação luminosa (IL) seria de cerca de $95 \%$ da radiação solar incidente. 
Experimento conduzido por Clapp Junior. et al. (1965) revelou valores de IAF entre 1,4 e 2,7 para Cynodon dactylon cv. Coastal, resultados semelhantes aos obtidos neste ensaio. Em trabalho mais recente, Gomide (1996) observou valores de IAF variando entre 1,68 e 5,85 para Tifton-85 e 1,19 e 5,89 para Florakirk avaliados aos 14 e 42 dias, respectivamente.

Tifton-85 apresentou um IAF consistentemente mais elevado que Florakirk $e$ esta, por sua vez, não diferiu de Coastcross (TABELA 2 e Figura 1). As diferenças varietais refletem a história evolutiva da população, sejam aquelas adquiridas naturalmente ou através de programas de melhoramento e seleção deliberados (Cooper, 1983; Madakadze et al. 1998). Os maiores valores de IAF para Tifton-85 devem estar associados a seu porte mais alto, com hastes grandes, folhas mais largas e compridas que os outros híbridos (Burton et al., 1993).

Pastos mantidos mais altos apresentaram os maiores valores de IAF, como seria esperado (TABELA 2 e Figura 2), de forma semelhante aos resultados encontrados por Clapp Junior et al. (1965) e Clavero Cepeda (1993). Os baixos valores de IAF encontrados em novembro e dezembro podem ter sido causados pela ocorrência de um período de estiagem bastante severo, com valores pluviométricos para o mês de novembro correspondentes à média mais baixa dos últimos 40 anos (26,8 vs $150 \mathrm{~mm}$ ) (ESALQ, 1999) (TABELA 1).

A interação entre cultivar e intensidade de pastejo para o IAF durante o período experimental é ilustrada pela mudança na ordem de classificação dos valores de IAF entre os cultivares para as intensidades de pastejo. Ou seja, até o mês de outubro, para as maiores intensidades de pastejo

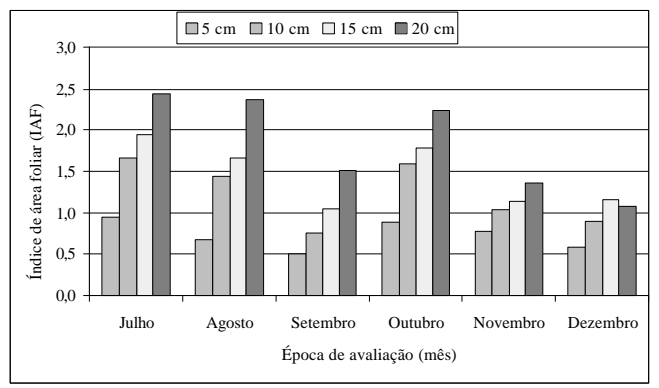

Figura 2 - Índice de área foliar em pastos de Cynodon spp. sob diferentes intensidades de pastejo e regime de lotação contínua ava liados em diferentes épocas do ano.
(5 e $10 \mathrm{~cm}$ ), os maiores valores de IAF foram apresentados por Tifton-85 seguidos de Florakirk e Coastcross. A partir de novembro, os valores de IAF da Florakirk foram igualados e superados pela Coastcross (TABELA 2). Estas diferenças deveram-se ao fato de que de agosto a novembro, Florakirk e Coastcross apresentaram desenvolvimento reprodutivo (florescimento) bastante intenso e contínuo, principalmente nas maiores alturas de pastejo, o que deve ter sido responsável por variações na estrutura do pasto relacionadas com mudanças nas proporções de haste e folha na forragem. Humphreys (1966) mencionou que Panicum maximum var trichoglume também apresentou um florescimento mais avançado em pastos pastejados lenientemente e quando limitações de umidade foram aparentes. De acordo com esse autor, o grau de florescimento foi negativamente relacionado à intensidade de desfolha, e as diferenças nos valores de IAF, induzidas pelas desfolhas, foram afetadas pelo florescimento. A partição de matéria seca é influenciada pela época e duração do estádio reprodutivo. O desenvolvimento da inflorescência nos perfilhos leva ao cessamento da emissão de novas folhas e também pode inibir o desenvolvimento de perfilhos de gemas axilares, levando a uma subsequente redução no rendimento (Cooper, 1983).

Segundo Cooper (1983) as diferenças relatadas entre e dentro de espécies forrageiras devem-se a algumas características do pasto como tamanho da folha, ângulo de inserção entre a folha e o caule, rigidez das folhas, etc., que podem afetar sua estrutura e, consequentemente, o IAF, a IL e o acúmulo de matéria seca.

\section{Interceptação Luminosa}

Os dados referentes a interceptação luminosa (IL) são mostrados na TABELA 3 e nas Figuras 3 e 4 . Houve diferenças entre os meses $(P=0,0001)$, cultivares $(P<0,0001)$, além da interação mês $x$ cultivar $(P=0,0001)$, as quais podem ser observadas na TABELA 3 e Figura 3. Houve interação mês $x$ altura $(P=0,001)$ e diferença entre alturas $(P=0,0001))$ (TABELA 3, Figura 4) e interação cultivar $x$ altura $(P=0,0003)$ (TABELA 3).

Coastcross apresentou menores valores de IL que Florakirk e Tifton-85 (TABELA 3, Figura 3). Isto é consistente com as variações em IAF (TABELA 2, Figura 1) e reflete, provavelmente, as diferenças morfológicas entre os cultivares. Em novembro e dezembro os valores de IL sofreram 
TABELA 3 - Interceptação luminosa de julho a dezembro de 1998 para os tratamentos (Cultivar x Altura) experimentais.

\begin{tabular}{|c|c|c|c|c|c|}
\hline Altura & Tifton-85 & Florakirk & Coastcross & média & EPM \\
\hline & & & Julho & & \\
\hline 5 & $21,2^{\mathrm{Ca}}$ & $24,6^{\mathrm{Ca}}$ & $30,1^{\mathrm{Da}}$ & $25,3^{\mathrm{C}}$ & 2,16 \\
\hline 10 & $80,7^{\mathrm{Ba}}$ & $73,1^{\text {Bab }}$ & $63,7^{\mathrm{Cb}}$ & $72,5^{\mathrm{B}}$ & 2,16 \\
\hline 15 & $94,3^{\mathrm{Aa}}$ & $92,8^{\mathrm{Aa}}$ & $79,0^{\mathrm{Bb}}$ & $88,7^{\mathrm{A}}$ & 2,16 \\
\hline 20 & 97,8 Aa & $94,2^{\mathrm{Aa}}$ & 89,9 Aa & $94,0^{\mathrm{A}}$ & 2,16 \\
\hline média & $73,5^{\mathrm{a}}$ & $71,2^{\mathrm{a}}$ & $65,7^{b}$ & & \\
\hline \multirow[t]{2}{*}{ EPM } & 1,87 & 1,87 & 1,87 & & \\
\hline & & & Agosto & & \\
\hline 5 & 36,6 Cab & $38,1^{\mathrm{Ca}}$ & $27,5^{\mathrm{Db}}$ & $34,1^{D}$ & 1,85 \\
\hline 10 & $70,7^{\mathrm{Ba}}$ & $67,2^{\mathrm{Ba}}$ & $55,4^{\mathrm{Cb}}$ & $64,4^{\mathrm{C}}$ & 1,85 \\
\hline 15 & $93,2^{\mathrm{Aa}}$ & $89,8^{\mathrm{Aa}}$ & $71,8^{\mathrm{Bb}}$ & $85,0^{\mathrm{B}}$ & 1,85 \\
\hline 20 & $97,4^{\mathrm{Aa}}$ & $93,6^{\mathrm{Aa}}$ & $84,3^{A b}$ & $91,8^{\mathrm{A}}$ & 1,85 \\
\hline média & $74,5^{a}$ & $72,2^{a}$ & $59,8^{b}$ & & \\
\hline \multirow[t]{2}{*}{ EPM } & 1,61 & 1,61 & 1,61 & & \\
\hline & & & Setembro & & \\
\hline 5 & $31,2^{\mathrm{Ca}}$ & $29,5^{\mathrm{Ca}}$ & $25,2^{\mathrm{Da}}$ & $28,6^{D}$ & 1,57 \\
\hline 10 & $74,5^{\mathrm{Ba}}$ & $70,3^{\mathrm{Ba}}$ & $50,0^{\mathrm{cb}}$ & $65,0^{\mathrm{C}}$ & 1,57 \\
\hline 15 & $92,1^{\mathrm{Aa}}$ & $85,7^{\mathrm{Aa}}$ & $66,9^{\mathrm{Bb}}$ & $81,5^{\text {B }}$ & 1,57 \\
\hline 20 & $97,2^{\mathrm{Aa}}$ & $91,8^{\mathrm{Aa}}$ & $81,6^{A b}$ & $90,2^{A}$ & 1,57 \\
\hline média & $73,7^{\mathrm{a}}$ & $69,3^{b}$ & $55,9^{c}$ & & \\
\hline \multirow[t]{2}{*}{ EPM } & 1,36 & 1,36 & 1,36 & & \\
\hline & & & Outubro & & \\
\hline 5 & $27,1^{\mathrm{Ca}}$ & $26,3^{\mathrm{Ca}}$ & $23,6^{\mathrm{Da}}$ & $25,7^{D}$ & 1,07 \\
\hline 10 & $72,6^{\mathrm{Ba}}$ & $70,1^{\mathrm{Ba}}$ & $56,5^{\mathrm{Cb}}$ & $66,4^{\mathrm{C}}$ & 1,07 \\
\hline 15 & $91,1^{\text {Aa }}$ & $88,3^{\text {Aa }}$ & $78,1^{\mathrm{Bb}}$ & $85,8^{\text {B }}$ & 1,07 \\
\hline 20 & $95,7^{\text {Aa }}$ & $93,4^{\mathrm{Aa}}$ & $86,7^{A b}$ & $91,9^{\mathrm{A}}$ & 1,07 \\
\hline média & $71,6^{a}$ & $69,5^{\mathrm{a}}$ & $61,2^{b}$ & & \\
\hline \multirow[t]{2}{*}{ EPM } & 0,93 & 0,93 & 0,93 & & \\
\hline & & & Novembro & & \\
\hline 5 & $26,7^{\mathrm{Ca}}$ & $22,4^{\mathrm{Dab}}$ & $19,0^{\mathrm{Db}}$ & $22,7^{D}$ & 1,49 \\
\hline 10 & $68,5^{\mathrm{Ba}}$ & $54,5^{\mathrm{Cb}}$ & $43,2^{\mathrm{cc}}$ & $55,4^{\mathrm{C}}$ & 1,49 \\
\hline 15 & $91,2^{\mathrm{Aa}}$ & $79,5^{\mathrm{Bb}}$ & $71,2^{\mathrm{BC}}$ & $80,6^{\text {B }}$ & 1,49 \\
\hline 20 & $96,1^{\mathrm{Aa}}$ & 90,9 Aa & $82,8^{A b}$ & $89,9^{A}$ & 1,49 \\
\hline média & $70,7^{a}$ & $61,8^{b}$ & $54,1^{\mathrm{c}}$ & & \\
\hline \multirow[t]{2}{*}{ EPM } & 1,29 & 1,29 & 1,29 & & \\
\hline & & & Dezembro & & \\
\hline 5 & $3,7 \mathrm{Ca}$ & $4,7^{\mathrm{Da}}$ & $5,3 \mathrm{Da}$ & $4,5^{\mathrm{D}}$ & 1,59 \\
\hline 10 & $41,3 \mathrm{Ba}$ & $29,6 \mathrm{cb}$ & $38,1^{\mathrm{Ca}}$ & $36,4^{c}$ & 1,59 \\
\hline 15 & $87,2 \mathrm{Aa}$ & $78,5^{\mathrm{Bb}}$ & $72,0^{\mathrm{Bb}}$ & $79,2^{\mathrm{B}}$ & 1,59 \\
\hline 20 & $93,3 \mathrm{Aa}$ & $89,0^{\mathrm{Aa}}$ & $86,3^{\mathrm{Aa}}$ & $89,5^{\mathrm{A}}$ & 1,59 \\
\hline média & $56,4 \mathrm{a}$ & $50,5^{b}$ & $50,4^{b}$ & & \\
\hline EPM & 1,38 & 1,38 & 1,38 & & \\
\hline
\end{tabular}

Médias seguidas de mesma letra não diferem entre si $(P>0,05)$, letra maiúscula na coluna e minúscula na linha. EPM - erro padrão da média.

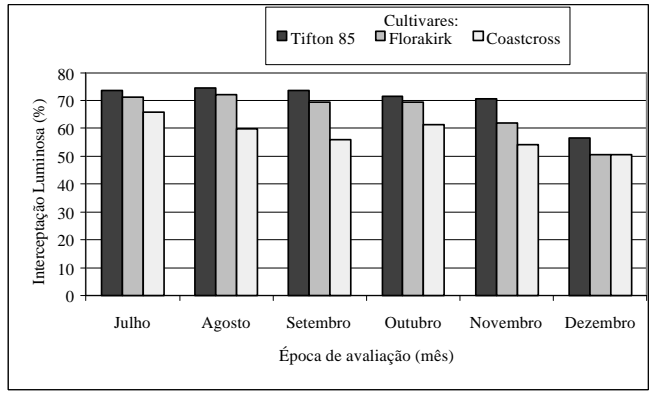

Figura 3 - Interceptação luminosa em pastos de Cynodon spp. sob regime de lotação contínua e em diferentes épocas de avaliação.

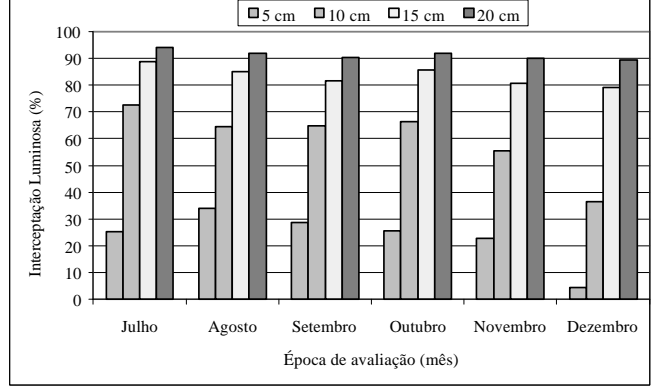

Figura 4 - Interceptação luminosa em pastos de Cynodon spp. sob diferentes intensida des de pastejo em regime de lotação con tínua avaliados em diferentes épocas do ano. 
uma diminuição, explicada pelos baixos valores de IAF observados naquele período. Madakadze et al. (1998) também apontaram uma íntima relação entre IL e IAF, com aumentos em IAF resultando num concomitante aumento da IL.

Pastos mantidos mais altos apresentaram os maiores valores de IL. Com o avanço da estação de crescimento houve uma estabilização nas diferenças ocorridas entre as intensidades de pastejo, ou seja, a partir do mês de setembro os tratamentos impostos mantiveram a mesma tendência estatística.

É fato amplamente reconhecido que quando o pasto intercepta $95 \%$ da luz incidente teria-se um valor de IAF dito crítico no qual a taxa de crescimento da cultura estaria próxima de um valor máximo (Brougham, 1956; da Silva \& Pedreira, 1997). Segundo esta premissa somente o cultivar Tifton-85, especialmente na menor intensidade de pastejo $(20 \mathrm{~cm})$, atingiu as condições necessárias para atingir a TCC máxima, uma vez que foi o único tratamento onde as plantas interceptaram esta proporção de luz incidente. Contudo, devido a outros fatores ambientais limitantes como baixo índice pluviométrico, particularmente em novembro, é provável que esse potencial não tenha sido alcançado.

Tomando-se por base o critério de $95 \%$ de IL como condição ótima para regulação de uso e colheita da planta, Tifton-85 estaria apta a ser colhida já a partir de $15 \mathrm{~cm}$. Coastcross, por sua vez, foi a que apresentou os menores valores de $\mathrm{IL}$, mesmo na altura de $20 \mathrm{~cm}$, valores estes muito inferiores aos 95\% considerados ideais. Florakirk apresentou comportamento intermediário.

$\mathrm{Na}$ condição de desfolha mais extrema $(5 \mathrm{~cm})$, o cultivar Tifton-85 interceptou, consistentemente, mais luz que os demais (TABELA 3). Assim poderia se inferir que Tifton-85 apresentaria uma flexibilidade, em termos de amplitude de altura de colheita, menor que Florakirk e Coastcross, uma vez que foi capaz de interceptar $95 \%$ de luz incidente já a partir de $15 \mathrm{~cm}$ de altura enquanto que Florakirk e Coastcross provavelmente atingiriam esse ponto em altura superior a $20 \mathrm{~cm}$.

Valores disponíveis na literatura em trabalhos que relacionam IAF e IL mostram que o IAF crítico, onde $95 \%$ da luz incidente seria interceptado, seria de aproximadamente 5,0 (Brougham, 1956). Os valores obtidos para Tifton85 no presente trabalho foram, em média, de 2,5. Valores desta mesma ordem de grandeza já haviam sido relatados por Clapp Junior et al. (1965) para Cynodon dactylon cv. Coastal, em ensaio conduzido no Estado da Carolina do Norte, nos Estados Unidos.
Provavelmente os valores de IL na altura de pastejo de $5 \mathrm{~cm}$ tenham sido subestimados, pois a leitura da radiação solar fotossinteticamente ativa acima do relvado e ao nível do solo é realizada através de um equipamento (sensor de barra) que possui lente para leitura a 2,8 cm do nível do solo, - que poderia estar gerando um erro consistentemente maior para a intensidade de pastejo de $5 \mathrm{~cm}$ relativamente às demais alturas. Brougham (1957) relata ter omitido valores de leituras de IL e IAF em seu estudo porque 0 equipamento utilizado para mensurações de IL tendeu a deslocar as folhas e acabou por subestimar esses valores nos estádios iniciais de desenvolvimento das plantas. Esse efeito foi negligenciável quando as plantas atingiram estádios mais avançados de crescimento.

Verifica-se que a interação entre cultivar e intensidade de pastejo para a IL durante o período experimental foi representada pela alteração na ordem de classificação dos cultivares ocorrida no mês de dezembro na intensidade de pastejo de 10 $\mathrm{cm}$, ou seja, a IL no cultivar Florakirk foi inferior em relação aos demais cultivares, comportamento inverso àquele observado durante os demais meses do ano e intensidades de pastejo.

Sheehy \& Cooper (1973) e Cooper (1983) mencionaram que a principal variável climática determinante da produção é a quantidade de energia luminosa incidente mas, na maioria dos ambientes de pastagens, o crescimento, ou até mesmo a sobrevivência das plantas, pode ser limitado por estresse térmico, hídrico ou nutricional. Durante o período experimental foram verificadas baixas precipitações pluviométricas no mês de novembro (TABELA 1), que reduziu o crescimento de todos os cultivares de Cynodon, em especial do cultivar Florakirk, que teve seu crescimento prejudicado nas maiores intensidades de pastejo durante os meses de novembro e dezembro. Este fato pode ser verificado através dos baixos valores de IAF na intensidade de pastejo de $10 \mathrm{~cm}$ (TABELA $2)$, os quais resultaram em baixos valores de IL (TABELA 3).

\section{Taxa de acúmulo de matéria seca}

Os dados de acúmulo de forragem são mostrados nas TABELAS 4 e 5 e Figuras 5 e 6 . Houve apenas diferenças entre meses $(P=0,0001)$ as quais podem ser observadas nas Figuras 5 e 6 .

Uma característica dos dados é um padrão de comportamento relativamente uniforme para as taxas de acúmulo de forragem com o decorrer da estação de 
TABELA 4 - Taxas de acúmulo de matéria seca ( $\mathrm{kg} \mathrm{MS} \mathrm{ha}^{-1} \mathrm{dia}^{-1}$ ) de agosto a dezembro de 1998 para os cultivares de Cynodon spp.

Mês Tifton-85 Florakirk Coastcross EPM

\begin{tabular}{lcccc}
\hline Agosto & $27,8^{\mathrm{b}}$ & $37,5^{\mathrm{ab}}$ & $40,0^{\mathrm{a}}$ & 4,20 \\
Setembro & $29,2^{\mathrm{ab}}$ & $24,5^{\mathrm{b}}$ & $35,3^{\mathrm{a}}$ & 2,30 \\
\hline Outubro & $70,6^{\mathrm{a}}$ & $52,3^{\mathrm{a}}$ & $70,1^{\mathrm{a}}$ & 6,90 \\
\hline Novembro & $57,1^{\mathrm{a}}$ & $38,2^{\mathrm{b}}$ & $50,7^{\mathrm{ab}}$ & 5,20 \\
\hline Dezembro & $104,3^{\mathrm{a}}$ & $79,2^{\mathrm{b}}$ & $84,4^{\mathrm{ab}}$ & 7,30 \\
\hline
\end{tabular}

Médias na mesma linha seguidas de letras semelhantes não diferem entre si $(P>0,05)$

EPM - erro padrão da média.

TABELA 5 - Taxas de acúmulo de matéria seca ( $\mathrm{kg} \mathrm{MS} \mathrm{ha}^{-1} \mathrm{dia}^{-1}$ ) de agosto a dezembro de 1998 para as alturas de pastejo em estudo.

\begin{tabular}{llllll}
\hline \multicolumn{1}{c}{ Mês } & $5 \mathrm{~cm}$ & $10 \mathrm{~cm}$ & $15 \mathrm{~cm}$ & $20 \mathrm{~cm}$ & EPM \\
\hline Agosto & $32,2^{\text {a }}$ & $36,8^{\text {a }}$ & $30,8^{\text {a }}$ & $40,6^{\text {a }}$ & 4,90 \\
Setembro & $29,7^{\text {a }}$ & $26,7^{\text {a }}$ & $30,4^{\text {a }}$ & $31,8^{\text {a }}$ & 2,70 \\
Outubro & $66,2^{\text {a }}$ & $65,3^{\text {a }}$ & $61,3^{\text {a }}$ & $64,6^{\text {a }}$ & 8,10 \\
Novembro & $46,6^{\text {ab }}$ & $38,1^{\mathrm{b}}$ & $46,6^{\text {a }}$ & $63,4^{\text {a }}$ & 6,10 \\
\hline Dezembro & $89,1^{\text {a }}$ & $90,2^{\text {a }}$ & $84,3^{\text {a }}$ & $93,5^{\text {a }}$ & 8,60 \\
\hline
\end{tabular}

Médias na mesma linha seguidas de letras semelhantes não diferem entre si $(P>0,05)$

EPM - erro padrão da média.

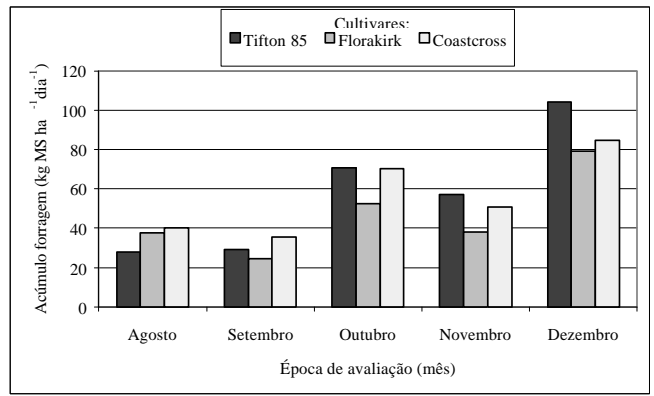

Figura 5 - Taxas de acúmulo de forragem em pastos de Cynodon spp. sob regime de lotação contínua e em diferentes épocas de avaliação.

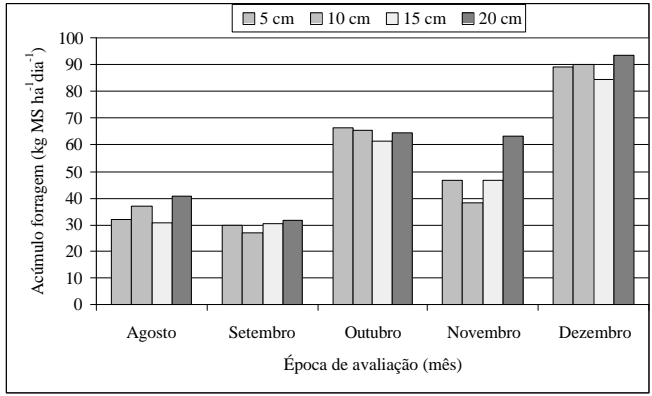

Figura 6 - Taxas de acúmulo de forragem em pastos de Cynodon spp. sob diferentes intensidades de pastejo em regime de lotação contínua avaliados em diferentes épocas do ano.

crescimento. Em novembro valores inferiores aos de outubro foram observados, provavelmente como conseqüência dos baixos índices pluviométricos, muito embora estes valores tenham sido superiores aos apresentados durante os meses de agosto e setembro.

De acordo com os resultados de Carnevalli \& da Silva (1999) os valores de taxa de acúmulo para Coastcross variaram entre 15,7 e $96,2 \mathrm{~kg} \mathrm{MS} \mathrm{ha}^{-1} \mathrm{dia}^{-1}$. No presente experimento os valores médios de taxa de acúmulo variaram entre 24,5 e $104,3 \mathrm{~kg} \mathrm{MS} \mathrm{ha}^{-1} \mathrm{dia}^{-1}$.

Trabalho realizado por Sheehy \& Cooper (1973) com várias espécies forrageiras em condições não limitantes de umidade e nutrientes no solo demonstrou grandes diferenças varietais em acúmulo de forragem, associando essas diferenças com variações na distribuição de luz dentro do dossel e sugerindo que a arquitetura do pasto seria um fator importante na determinação da taxa de crescimento das culturas.

Brougham (1956) sugeriu que valores de IL acima de $95 \%$ resultariam em máxima atividade fotossintética e, portanto, em máxima taxa de crescimento. No presente experimento valores de IL iguais ou maiores que $95 \%$ só foram atingidos por Tifton-85, mas este valor não foi refletido em taxa de acúmulo superior em relação aos demais cultivares devido às condições ambientais adversas. Humphreys (1966), trabalhando com Panicum maximum var trichoglume, destacou que o crescimento foi independente da intensidade de desfolha, resultados esses que corroboram aqueles obtidos no presente ensaio. 
Hodgson (1990) caracterizou o processo de acúmulo de forragem como sendo o saldo do balanço entre o crescimento (produção de novos tecidos - folhas e hastes) e a senescência /morte. Pastos submetidos a regimes de desfolha intensos apresentam pequeno crescimento mas, em contrapartida, baixa senescência. Por outro lado, pastos submetidos a regimes de desfolha lenientes apresentam crescimento mais acelerado que é, em contrapartida, compensado por taxas maiores de senescência e morte de tecidos (Tainton, 1974). Deve existir, portanto uma amplitude de combinações e possibilidades de regime de desfolha que geram um mesmo equilíbrio, produção de forragem, a partir de balanços diferentes entre crescimento e senescência (Hodgson, 1990). Os tratamentos empregados no presente ensaio podem fazer parte dessa amplitude de possibilidades o que resultaria em produções semelhantes de matéria seca.

Segundo Clavero Cepeda (1993) outros fatores contribuem para a falta de consistência da relação entre IL, IAF e taxa de acúmulo de matéria seca, uma vez que plantas interagem dinamicamente com outros componentes do ambiente.

\section{CONCLUSÕES}

Os maiores valores de IAF foram encontrados para Tifton-85. As taxas de acúmulo de matéria seca foram semelhantes em todos os tratamentos. Tifton-85 apresentou, como amplitude ótima de uso, condições de pasto que variaram de 5 a $15 \mathrm{~cm}$, já para a Florakirk essa faixa foi até 20 $\mathrm{cm}$ e para Coastcross o limite superior seria maior que $20 \mathrm{~cm}$. Diferentes cultivares apresentaram requerimentos variados de manejo de desfolha quando o objetivo foi o uso eficiente da luz e demais fatores de crescimento e elevados índices de utilização da forragem produzida.

\section{AGRADECIMENTOS}

Aos estagiários do Grupo de Estudo com Plantas Forrageiras, que ajudaram na instalação, condução e análise deste experimento. À CAPES pela concessão da bolsa de estudos, e à FAPESP pelo financiamento do programa de pesquisa.

\section{REFERÊNCIAS BIBLIOGRÁFICAS}

BROUGHAM, R.M. Interception of light by the foliage of pure and mixed stands of pasture plants. Australian Journal of Agricultural Research, v.9, p.39-52, 1957.
BROUGHAM, R.M. Effects of intensity of defoliation on regrowth of pastures. Australian Journal of Agricultural Research, v.7, n.5, p.377-387, 1956.

BROWN, R.H.; BLASER, R.E. Leaf area index in pasture growth. Herbage Abstracts, v.38, n.1, p.1-9, 1968.

BURTON, G.W.; GATES, R.N.; HILL, G.M. Registration of Tifton-85 bermudagrass. Crop Science, v.33, p.644-645, 1993.

CARNEVALLI, R.A.; DA SILVA, S.C. Validação de técnicas experimentais para avaliação de características agronômicas e ecológicas de pastagens de Cynodon dactylon cv. Coastcross1. Scientia Agricola, v.56, n.2, 489-499, 1999.

CLAPP JUNIOR, J.G.; CHAMBLEE, B.S.; GROSS, H.D. Interrelationschips between defoliation systems, morphological characteristics and growth of 'Coastal bermudagrass'. Crop Science, v.5, p.428-471, 1965.

CLAVERO CEPEDA, T. Efecto de la defolación sobre el crescimento, área foliar e intercepción de luz en pastos tropicales. Revista de la Facultad de Agronomía de la Universidad del Zulia, v.10, n.1, p.57-67, 1993.

COOPER, J.P. Physiological and morphological advances for forage improvement In: INTERNATIONAL GRASSLAND CONGRESS, 14., Lexington, 1981. Proceedings. Boulder: Westview Press, 1983.

DAVIES, D.A.; FURTHERGILL, M.; MORGAN, C.T. Assessment of contrasting perenial ryegrasses and white clover under continuous stocking in the uplands. 5 - Herbage production, quality and intake in years 4-6. Grass and Forage Science, v.48, n.3, p.213-222, 1993.

DA SILVA, S.C.; PEDREIRA, C.G.S. Princípios de ecologia aplicados ao manejo de pastagem. In: SIMPÓSIO SOBRE ECOSSISTEMA DE PASTAGENS, 3, Jaboticabal, 1997. Anais. Jaboticabal: UNESP, FCAV / FUNEP, 1997. p1-62.

ESALQ. Departamento de Ciências Exatas http:/ /www.ciagri.usp.br/ emdabreu/MEDIAS.txt (06 Jan. 1999)

GOMIDE, C.C.C. Algumas características fisiológicas e químicas de cinco cultivares de Cynodon. Jaboticabal, 1996. 100p. Dissertação (Mestrado)Faculdade de Ciências Agrárias e Veterinárias, Universidade Estadual Paulista "Júlio de Mesquita Filho".

HODGSON, J.G. Grazing management: science into pratice. Harlow: Longman Scientific \& Technical, 1990. 203p.

HUMPHREYS, L.R. Subtropical grass growth: II Effects of variation in leaf area index in the field. Queenland Journal of Agricultural and Animal Sciences, v.23, p.388-358, 1966. 
HUMPHREYS, L.R. Tropical pasture utilisation. Cambridge: Cambridge University Press, 1991, 206p.

MADAKADZE, I.C.; COULMAN, B.E.; PETERSON, P.; STEWART, K.A.; SAMSON, R.; SMITH, D.L. Leaf area development, light interception, and yield among switchgrass populations in a shortseason area. Crop Science, v.38, p.827-834, 1998.

RHODES, I. Relationship between canopy structure and productivity in herbage grasses and its implication for plant breeding. Herbage Abstracts, v.43, p.129-133, 1973.

SAS INSTITUTE. SAS user's guide: realese. 6.03 Cary: Statistical Analysis System Institute, 1988. 1028p.
SHEEHY, J.E.; COOPER, J.P. Light interception, photosynthetic activity, and crop growth rate in canopies of six temperate forage grasses. Journal of Applied Ecology, v.10, p.239-250, 1973.

TAINTON, N.M. A comparison of different pasture rotations. Proceedings of the New Zealand Grassland Association, v.35, p.204-210, 1974.

WATSON, D.J. The dependence of net assimilation on leaf area index. Annals of Botany, v.22, p.37-54, 1958.

Recebido para publicação em 26.02.99

Aceito para publicação em 13.09 .99 